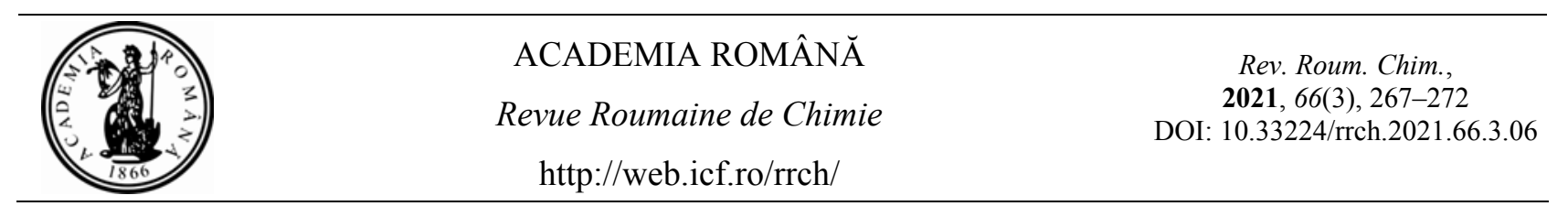

\title{
ASSESSING OPERATIONAL INACTIVATION OF HORSERADISH PEROXIDASE DURING BRILLIANT BLUE G DECOLORIZATION
}

\author{
Delia MĂRTINAŞ, Mihaela PUIU, Petruța OANCEA and Adina RĂDUCAN* \\ Department of Physical Chemistry, Faculty of Chemistry, University of Bucharest, 4-12 Elisabeta Blvd., \\ 030018, Bucharest, Roumania
}

Received September 28, 2020

An efficiency study about the horseradish peroxidase (HRP) activity over Brilliant Blue-G (BB) decolorization with hydrogen peroxide was achieved through kinetic analysis. Differential and extended kinetic curves were used for assessing the inactivation paths and for optimizing the overall degradation process. The catalytic and the specificity constants estimated via MichaelisMenten model demonstrated that HRP is highly efficient in dye decolorization, although operational inactivation due to formation of degradation products still occurred. It was noticed that the bicarbonate anions exerted protective effects on the enzyme inactivation caused by the oxidizing substrate but affected less the inactivation due to the degradation products of BB.

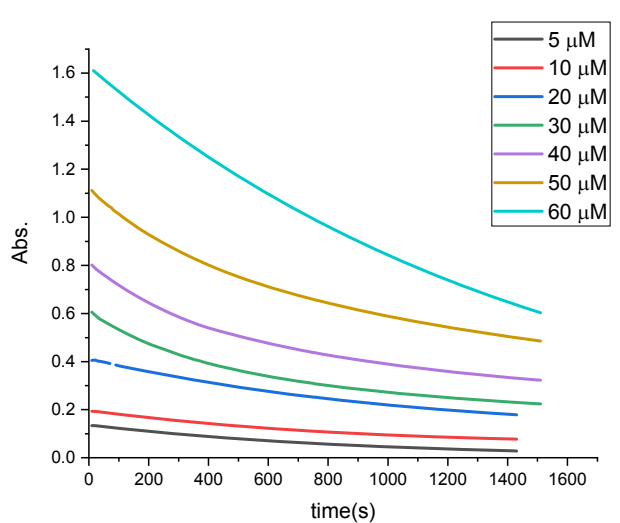

Coomassie Brilliant Blue or Brilliant Blue-G (BB) is a triphenylmethane dye, frequently used for protein analysis in biochemistry ${ }^{4}$, as colouring agent in retinal surgery ${ }^{5}$, and for dyeing synthetic and natural fibres. Its main strengths are high stability and low cost, but ultimately this dye becomes harmful after long exposure, affecting kidneys. ${ }^{6}$

Chemical and biological methods are currently used for BB degradation, including photocatalysis with nickel- $^{7}$ and other metal-oxides catalysts ${ }^{8}$ under ultraviolet (UV) or visible (VIS) light, and biological removal. ${ }^{9}$ The advanced oxidation processes (AOPs) conduct the oxidation to mineralization but involve high costs due to catalysts synthesis steps and significant amounts of

\footnotetext{
*Corresponding author: adina.raducan@g.unibuc.ro
} 
energy spent during the overall process. On the other hand, biological methods are cost-effective and eco-friendly, but they are also time consuming. ${ }^{10}$ An optimal and efficient degradation method must match at least two criteria such as economic efficiency and use/release of few environmentally toxic compounds. The aim is to achieve the 'green chemistry' features, focusing on the transformation of dyes into colourless and nonharmful compounds for the living things. ${ }^{10}$

HRP is a haem-containing oxidoreductase, with a catalytic site containing two atoms of calcium and one iron (III) protoporphyrin that acts as electron donor on hydrogen peroxide. HRP catalyses the oxidation of several aromatic compounds (phenols and amines) in presence of $\mathrm{H}_{2} \mathrm{O}_{2}{ }^{11,12} \mathrm{HRP}$ is involved in environmental remediation, treatment of wastewaters, elimination of toxic compounds (dyes) from drinking and industrial water. ${ }^{13-16}$ Bicarbonate is widely distributed in biological systems and in nature, highly soluble in water and exists in various form constituting the main biological buffer. However, it has encouraging properties for its application in the wastewater treatment. For example, it is inexpensive, it can activate $\mathrm{H}_{2} \mathrm{O}_{2}$ and displays buffering capacity $(\mathrm{pH}$ 8.0-9.0). These are attractive properties in the development of a sustainable wastewater treatment. Various reactive oxygen species (ROS), such as $\bullet \mathrm{OH}, \bullet \mathrm{O}_{2}^{-}$and ${ }^{1} \mathrm{O}_{2}$, drive the pollutants' degradation. The generation of another reactive species $\left(\mathrm{HCO}_{4}^{-}, \bullet \mathrm{CO}_{3}^{-}, \bullet \mathrm{HCO}_{3}\right)$ together with the previously mentioned ROS have been reported as bicarbonate activated hydrogen peroxide (BAP) system in recent works. ${ }^{17,18}$

In this study we pursued Brilliant Blue-G degradation in the presence of HRP, in conditions that mimics natural/ambient conditions (i.e. unbuffered media, presence of bicarbonate anions). Mixing enzymatic/chemical treatment (BAP-HRP have distinctive advantages. First, HRP is capable to decolourize the dye to smaller by-products or intermediates; then, these species are further oxidized to unharmful low molecular weight compounds by the BAP system.

\section{RESULTS AND DISCUSSION}

The degradation process was monitored at fixed wavelength $(\lambda=619 \mathrm{~nm})$, where the absorption band of $\mathrm{BB}$ reached its maximum. The progress kinetic curves absorbance vs. time were recorded in reaction mixtures containing $\mathrm{BB}, \mathrm{H}_{2} \mathrm{O}_{2}$, $\mathrm{NaHCO}_{3}$ and HRP (Fig. 1).

Non-linear regression analysis was performed onto extended kinetic curves absorbance vs. time. The best fit parameters were obtained for the exponential decay (eq. 1).

$$
A=A_{1} e^{-\frac{t}{t_{1}}}
$$

where $A_{l}$ is the dye absorbance at the beginning of the experiment, $A$ is the concentration at a given time $t$ and $t_{1}$ represents the lifetime. The initial reaction rate was estimated by deriving eq. $1 \mathrm{t}=0$ and considering the $\mathrm{BB}$ concentration as:

$$
[B B]=\frac{A}{\varepsilon^{B B} l}
$$

Here $\varepsilon$ is the molar absorptivity and $l$ is the path length.

Therefore, the calculated initial rate becomes:

$$
r_{R}^{0}=\left(-\frac{d[B B]}{d t}\right)_{t=0}=-\frac{1}{\varepsilon^{B B} l}\left(\frac{d A}{d t}\right)_{t=0}=\frac{A_{1}}{\varepsilon^{B B} l t_{1}}
$$

The initial rates were used further to assess the enzymatic pattern of BB decolorization process.

\section{Determination of rate laws using initial conditions}

It was noticed that the variation of initial rates $v s$. BB concentration (Figure 2) follows a hyperbolic pattern characteristic to Michaelis-Menten kinetics; the maximum reaction rate $\left(r_{\max }\right)$ and the Michaelis constant $\left(K_{M}\right)$ were estimated through nonlinear regression using the theoretical model (eq. 4) and the experimental data from Fig. 2.

$$
r_{R}^{0}=\frac{r_{\max }}{1+\frac{K_{M}}{[B B]_{0}}}
$$

The estimated maximum rate was $r_{r \max }=$ $(9,00 \pm 1.12) 10^{-8} \mathrm{M} / \mathrm{s}$, while the Michaelis constant was $\mathrm{K}_{\mathrm{M}}=(7.71 \pm 0.54) 10^{-5} \mathrm{M}$ (with a determination coefficient $\left.R^{2}=0.9902\right)$. This values confirm the high affinity of $\mathrm{HRP}$ for $\mathrm{BB}$, with the estimated $\mathrm{K}_{\mathrm{M}}$ within the same range as for other triphenylmethane dyes such as Malachite Green or Crystal Violet. ${ }^{19}$ One parameter accounting the catalytic efficiency of the enzyme is the turnover frequency (or the catalytic constant $k_{\text {cat }}$ ) calculated as:

$$
k_{c a t}=\frac{r_{\max }}{[H R P]_{0}}
$$




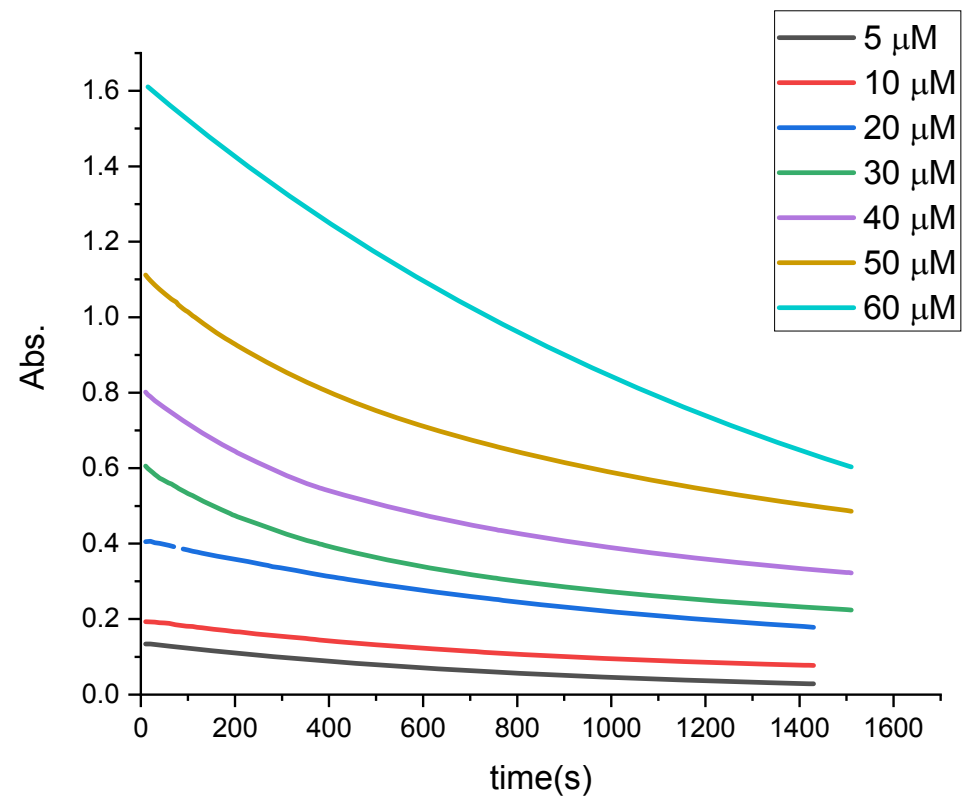

Fig. 1 - Decolorization progress of $\mathrm{BB}$ in $\mathrm{HRP} / \mathrm{HCO}_{3}{ }^{-} / \mathrm{H}_{2} \mathrm{O}_{2}$ system, monitored at several initial concentrations of $\mathrm{BB}$ $\left([\mathrm{HRP}]_{0}=0.2 \mu \mathrm{M},\left[\mathrm{H}_{2} \mathrm{O}_{2}\right]_{0}=1 \mathrm{mM},\left[\mathrm{HCO}_{3}^{-}\right]_{0}=10 \mathrm{mM}, \mathrm{T}=25^{\circ} \mathrm{C}\right)$.

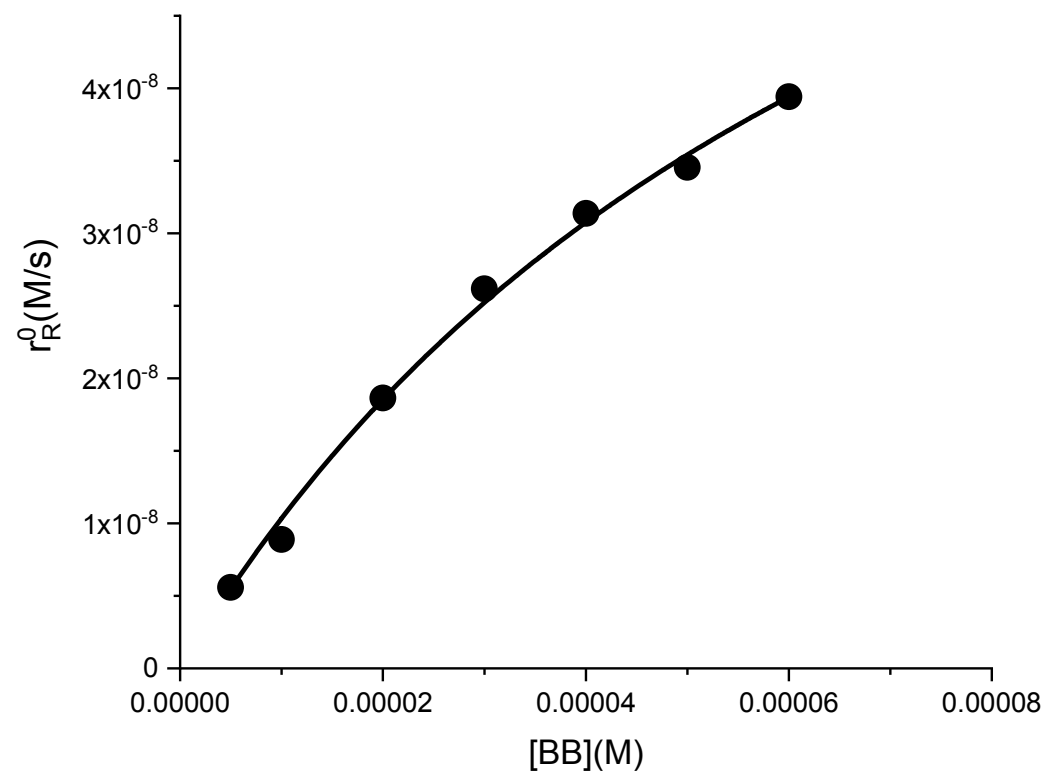

Fig. 2 -Variation of initial rates with $\mathrm{BB}$ concentration (solid line represents the best-fit Michaelis-Menten pattern) $\left([\mathrm{HRP}]_{0}=0.2\right.$ $\left.\mu \mathrm{M},\left[\mathrm{H}_{2} \mathrm{O}_{2}\right]_{0}=1 \mathrm{mM},\left[\mathrm{HCO}_{3}^{-}\right]_{0}=10 \mathrm{mM}, \mathrm{T}=25^{\circ} \mathrm{C}\right)$.

The turnover frequency corresponds to the number of molecules reacting per active site per unit time. ${ }^{20}$ Since the enzyme concentration (in protein) was around $10^{-7} \mathrm{M}$, the catalytic constant calculated with eq. 5 was $k_{\text {cat }}=0.9 \mathrm{~s}^{-1}$, value comparable or higher than those reported for other organic substrates $\left(0.82 \mathrm{~s}^{-1}\right.$ for veratryl alcohol, $0.05 \mathrm{~s}^{-1}$ for guaiacol). ${ }^{19}$ Another parameter used for the determination of the catalytic efficiency is the specificity constant (eq. 6):

$$
k_{s p}=\frac{k_{c a t}}{K_{M}}
$$

Interestingly, the obtained value for specificiy constant $k_{s p}=1.1610^{4} \mathrm{M}^{-1} \mathrm{~s}^{-1}$ is higher than those reported for the enzymatic degradation of other dyes with a bacterial peroxidase $\left(210^{2} \mathrm{M}^{-1} \mathrm{~s}^{-1}\right.$ for reactive blue 19). ${ }^{21}$

The initial rates estimated at settled $\mathrm{BB}$ and HRP concentrations but varying the initial 
hydrogen peroxide within $0.5-5 \mathrm{mM}$ and sodium bicarbonate within $0.002-0.1 \mathrm{M}$, do not differ significantly from the data presented in Fig.2. It was noticed that the initial rate of enzymatic reaction slightly increases in the presence of bicarbonate anions. Since no decrease of initial rates was observed at high $\mathrm{H}_{2} \mathrm{O}_{2}$ concentrations, it can be concluded that no inactivation occurred, at least no inactivation due to $\mathrm{H}_{2} \mathrm{O}_{2}$. This is quite unusual since extensively body of work dedicated to HRP-catalysed oxidation reports HRP inactivation through the formation of a peroxy$\mathrm{Fe}(\mathrm{III})$ - porphyrin free radical (Compound III) in excess $\mathrm{H}_{2} \mathrm{O}_{2}$. 22

\section{Testing the operational inactivation of HRP}

The peroxidase catalytic cycle involves distinct intermediate enzyme forms according to the ,pingpong" mechanism, ${ }^{23}$ but in specific conditions the inactivation of enzyme occurs through the formation of an low reactive intermediate, designated as Compound III. ${ }^{24}$ The examination of extended progress curves (concentration of either substrate or product $v s$. time) performed at settled initial concentration of substrates and different initial enzyme concentration, allows the estimation of the overall inactivation constant using an isoconversional method. ${ }^{25}$ The method involves the determination of the time values $\left(t_{1}, t_{2}, t_{3}\right.$ etc.) corresponding to a settled substrate concentration from the curves $[S]=f($ time $)$ achieved for the same initial substrate concentrations and different enzyme concentrations $[E]_{0}$. The first derivatives with respect to time $(d[S] / d t)_{i}$ are then estimated by numerical derivation at each time $t_{1}$, $t_{2}$, etc. For a first order inactivation, the overall inactivation rate constant $k_{\text {in }}$ can be estimated from linear regression on eq. 7 :

$$
\left.\ln \mid(d[S] / d t)_{i} \cdot 1 /[E]_{0, i}\right\rfloor=\ln f([S])-k_{\text {in }} \cdot t_{i}
$$

This method was previously used to detect the suicide inactivation of catalase at high substrate concentration, thermo-inactivation of catalase and urease. ${ }^{25}$ For HRP, the reported inactivation rate constants was around $10^{-3} \mathrm{~s}^{-1}$ for guaiacol and capsaicin ${ }^{26}$ and $10^{-2} \mathrm{~s}^{-1}$ for 2-aminophenol. ${ }^{27}$ In the case of $\mathrm{BB}$ oxidation, the isoconversional times were calculated for two settled values of BB concentration, corresponding to an initial part of reaction when $15 \%$ of $\mathrm{BB}$ is decomposed and at moderate substrate conversion, when $50 \%$ of $\mathrm{BB}$ is decomposed. In both cases the linear model from eq. 7 fitted well on experimental data, allowing the calculation of the overall inactivation constant using the slopes of the straight lines (Fig. 3).

It can be observed that for both moderate and low substrate conversions, the inactivation constants are of the same order of magnitude, the average value being $(6.19 \pm 0.52) 10^{-3} \mathrm{~s}^{-1}$. However, at high substrate conversions, the inactivation rate constant underwent a slightly increase, suggesting that additional inactivation of HRP by the products of BB degradation may have occurred.

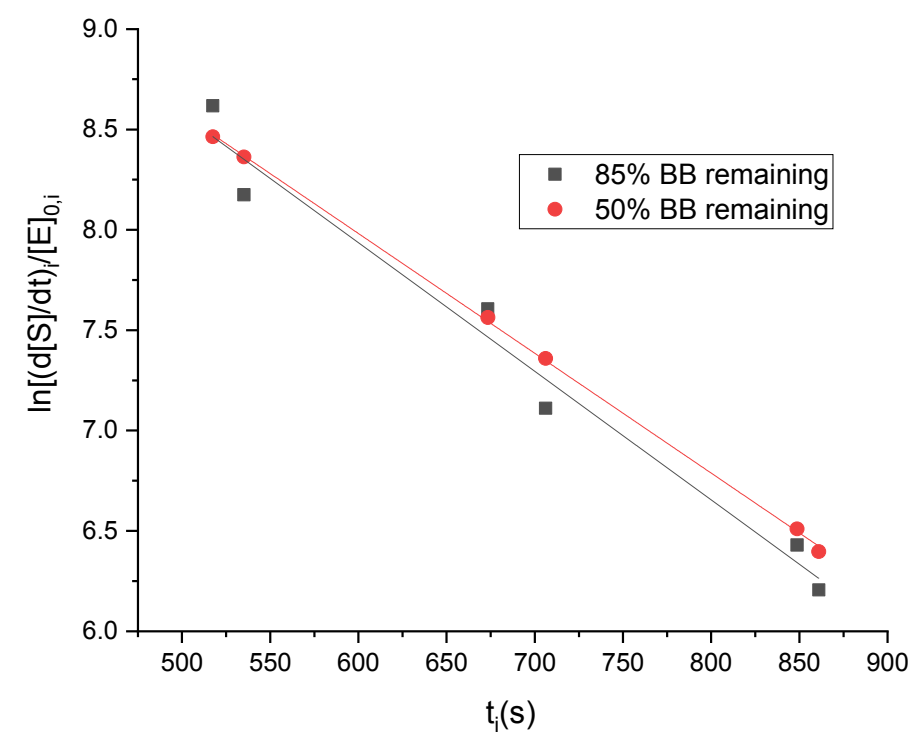

Fig. 3 - Estimation of the global inactivation rate constant using the isoconversional method (solid lines represent the linear fit of eq. 


\section{EXPERIMENTAL}

\section{Materials}

HRP (specific activity of $1280 \mathrm{U} / \mathrm{mg}$ solid matter, ABTS method) was obtained from Sigma. The enzymatic solutions were prepared in a $0.02 \mathrm{M}$ sodium phosphate buffer ( $\mathrm{pH} 7.0)$. All other reagents obtained from Sigma were of analytical grade and were used as received without further purification. $\mathrm{H}_{2} \mathrm{O}_{2} 30 \%$ was diluted and the concentration was measured spectrophotometrically with $\varepsilon_{240 \mathrm{~nm}}=39.4 \mathrm{M}^{-1} \mathrm{~cm}^{-1} .{ }^{28}$ The final enzyme concentration in the reaction mixture ranged between $410^{-8}$ and $410^{-7} \mathrm{M}$ was determined spectrophotometrically using the molar absorptivity $\varepsilon_{403 \mathrm{~nm}}=102000 \mathrm{M}^{-1} \mathrm{~cm}^{-1}$.

\section{Degradation experiments}

The kinetics of Brilliant Blue G (BB) degradation in the presence of HRP and sodium bicarbonate has been studied by a spectrophotometric method with a JASCO V-350 using $\mathrm{H}_{2} \mathrm{O}_{2}$ as oxidizing substrate. The reaction was carried out at $25^{\circ} \mathrm{C}$ for 30 minutes with $3 \mathrm{~mL}$ of the reaction mixture containing $\mathrm{HRP}, \mathrm{BB}, \mathrm{NaHCO}_{3}$ and $\mathrm{H}_{2} \mathrm{O}_{2}$. The characteristic absorbances of $\mathrm{BB}$ were measured at $\lambda=619 \mathrm{~nm}$ (using the molar absorptivity $\varepsilon_{619 \mathrm{~nm}}=27033 \mathrm{M}^{-1} \mathrm{~cm}^{-1}$, estimated from a calibration curve absorbance vs. concentration for $\mathrm{BB}$ solutions $(2-70 \mu \mathrm{M})$ in bicarbonate $0.01 \mathrm{M})$ in time to obtain extended kinetic curves. Data were processed using the ORIGIN 8.0 software. To study the influence of the initial concentrations of $\mathrm{BB}, \mathrm{NaHCO}_{3}, \mathrm{H}_{2} \mathrm{O}_{2}$ and HRP, the isolation method, where all the initial concentrations except one are kept constant, was used. The initial concentrations kept constant were: $[\mathrm{BB}]_{0}=20 \mu \mathrm{M} ; \quad\left[\mathrm{NaHCO}_{3}\right]_{0}=0.01 \mathrm{M}$; $\left[\mathrm{H}_{2} \mathrm{O}_{2}\right]_{0}=1 \mathrm{mM}$ and $[\mathrm{HRP}]_{0}=0.2 \mu \mathrm{M}$ (in protein).

\section{CONCLUSIONS}

It was found that he HRP-catalysed oxidation of $\mathrm{BB}$ with $\mathrm{H}_{2} \mathrm{O}_{2}$ in the presence of bicarbonate anions follows a Michaelis-Menten pattern. The estimated kinetic parameters of the MichaelisMenten were used further to investigate possible inactivation pathways of enzyme. The values of maximum reaction rate and the Michaelis constant, estimated by nonlinear regression, showed good specificity and efficiency of HRP for BB, a total discoloration of $\mathrm{BB}$ being acquired in less than 1 hour. The presence of bicarbonate anions induces a slightly increase of the initial reaction rate, suggesting that these anions may exert a protective effect against $\mathrm{HRP}$ inactivation at higher $\mathrm{H}_{2} \mathrm{O}_{2}$ levels. The examination of the extend kinetic curves demonstrates that the inactivation of HRP still occurs, but it may be caused by the degradation products of BB. This hypothesis is sustained by the increase of the overall inactivation constants at higher conversions of BB. The inactivation was not caused by the dye substrate per se, because the increase initial rates along with BB concentrations, clearly excluded this assumption. These findings may be used to exploit the ubiquitous presence of bicarbonate anions in surface waters to reduce the content of contaminated effluents from textile industry trough peroxidase-catalysed oxidation.

\section{REFERENCES}

1. M. Sievers, "Advanced Oxidation Processes" in "Treatise of Water Sciences", vol. 4, P. Wilderer (Ed.), Elsevier B. V., Amsterdam, 2011, p. 377-408.

2. S. U. Jadhav, M. U. Jadhav, A. N. Kagalkar and S. P. Govindwar, J. Chin. Inst. Chem. Eng., 2008, 39, 563570.

3. B. Lellis, C. Z. Fávaro-Polonio, J. A. Pamphile and J. C. Polonio, Biotechnol. Res. Innov., 2019, 3, 275-290.

4. R. W. Congdon, G. W. Muth and A. G. Splittgerber, Anal. Biochem., 1993, 213, 407-413.

5. M. Remy, S. Thaler, R. G. Schumann, C. A. May, M. Fiedorowicz, F. Schuettauf, M. Grüterich, S. G. Priglinger, M. M. Nentwich, A. Kampik and C. Haritoglou., Brit. J. Ophthalmol., 2008, 92, 1142-1147.

6. E. Mohamed, I. Abo-laila and M. A. Masoud, J. Drug Deliv. Ther., 2019, 9, 1-8.

7. M. F. Hanafi and N. Sapawe, Mater. Today Proc., 2020, 31, 318-320.

8. R. Gusain, K. Gupta, P. Joshi and O. P. Khatri, Adv. Colloid. Interfac., 2019, 272, 2-23.

9. S. Varjani, P. Rakholiya, H. Y. Ng, S. You and J. A. Teixeira, Bioresource Technol., 2020, 314, 1-8.

10. B. Mishra, S. Varjani, D. C. Agrawal, S. K. Mandal, H. H. Ngo, M. J. Taherzadeh, J.-S. Chang, S. You and W. Guo, Environ. Technol. Innov., 2020, 20, 1-17.

11. A. M. Azevedo, V. C. Martins, D. M. F. Prazeres, V. Vojinović, J. M. S. Cabral and L. P. Fonseca, "Horseradish peroxidase: a valuable tool in biotechnology", in Biotechnol. Annu. Rev., vol. 9, Elsevier, Amsterdam, 2003, p. 199-247.

12. M. Bilal, M. Adeel, T. Rasheed, Y. Zhao and H. M. N. Iqbal, Environ. Int., 2019, 124, 336-353.

13. J. Zdarta, A. S. Meyer, T. Jesionowski and M. Pinelo, Adv. Colloid. Interfac., 2018, 258, 1-20.

14. S. V. Mohan, K. K. Prasad, N. C. Rao and P. N. Sarma, Chemosphere, 2005, 58, 1097-1105.

15. Z. Vujčić, B. Janović, N. Lončar, A. Margetić, N. Božić, B. Dojnov and M. Vujčić, Int. Biodeter. Biodegr., 2015, 97, 124-127.

16. P. Dhankhar, V. Dalal, J. K. Mahto, B. R. Gurjar, S. Tomar, A. K. Sharma and P. Kumar, Arch. Biochem. Biophys., 2020, 693, 1-15.

17. A. Jawad, Z. Chen, G. Yin, Chinese J. Catal., 2016, 37, 810-825.

18. A. Răducan, M. Puiu, P. Oancea, C. Colbea, A. Velea, B. Dinu, A. M. Mihăilescu and T. Galaon, Sep. Purif. Technol., 2019, 210, 698-709.

19. K. Shin, I. Oh and C. Kim, Appl. Environ. Microbiol., 1997, 63, $1744-1748$.

20. S. Kozuch and J. M. L. Martin, ACS Catal., 2012, 2, 2787-2794. 
21. A. K. Chaplin, M. T. Wilson and J. A. R. Worrall, Dalton T., 2017, 46, 9420-9429.

22. H. B. Dunford, "Heme Peroxidases", New York: WileyVCH, 1999, p. 284-290.

23. S. Savic, K. Vojinovic, S. Milenkovic, A. Smelcerovic, M. Lamshoeft and Z. Petronijevic, Food Chem., 2013, 141, 4194-4199.

24. S. A. Adediran and A.-M. Lambeir, Eur. J. Biochem., 1989, 186, 571-576.
25. D. Oancea, A. Stuparu, M. Nita, M. Puiu and A. Raducan, Biophys. Chem., 2008, 138, 50-54.

26. A. R. Leonties, A. Raducan, M. Puiu and D. Oancea, Rev. Roum. Chim., 2014, 59, 669-674.

27. M. Puiu, M. Constantinovici, I. Babaligea, A. Raducan, C. Olmazu and D. Oancea, Chem. Eng. Technol., 2010, $33,414-420$.

28. H. Theorell and A. Ehrenberg, Arch. Biochem. Biophys., 1952, 41, 462-474. 